\title{
0 ATIVISMO JUDICIAL COMO PROBLEMA INTELECTUAL E POLÍTICO NOS ESTADOS UNIDOS: UMA ANÁLISE CRÍTICA*
}

\author{
Andrei Koerner \\ Professor de Ciência Política do IFCH-Unicamp; pesquisador do INCT-Ineu e pesquisador \\ associado do Cedec. São Paulo,SP.Brasil.E-mail: <andreik@uol.com.br>
}

http://dx.doi.org/10.1590/ 0102-6445233-255/99

Ativismo judicial é um termo utilizado para apreciar as instituições e agentes judiciais nas democracias contemporâneas, com o qual se coloca o problema do papel apropriado do Poder Judiciário, o modelo de decisão judicial e o comportamento dos juízes. O termo e seu contraponto, a autocontenção, têm como foco a autonomia de julgamento do juiz na construção do caso e a tomada de decisão. Essa autonomia se dá no espaço aberto entre os quadros normativos gerais e os dados fáticos de uma situação sob julgamento, e parece insuprimível desde a crítica realista aos modelos formalistas e analíticos. Os críticos do ativismo pressupõem um modelo de decisão - ou indicam-no como ideal normativo - que seria capaz de retomar a univocidade das normas e a determinação das decisões, e que permitiria justificar a atuação dos juízes numa democracia constitucional. É dessa forma que, de

\footnotetext{
* Análise resumida sobre o tema foi apresentada em Koerner (2013). Este artigo resulta de atividades realizadas pelo Grupo de Pesquisas sobre Direito e Política do Centro de Estudos Internacionais e de Política Contemporânea (GPD/Ceipoc) da Unicamp, no quadro de atividades do INCT/Ineu.
} 
modo geral, o problema tem sido trabalhado em teoria do direito, filosofia do direito e filosofia moral.

O termo ativismo judicial disseminou-se no debate político e acadêmico, inicialmente nos Estados Unidos e, mais tarde, noutros países. Mas o termo, tanto quanto o seu contraponto, a autocontenção, têm sido criticados por suas ambiguidades, vieses e efeitos políticos. As críticas foram sucedidas por tentativas de teorização e refinamento conceitual, em disciplinas como teoria e sociologia do direito, história e ciência política. Os termos foram incorporados à agenda dessa disciplina, e passaram a integrar os esquemas conceituais com os quais se analisam os temas relativos ao Judiciário.

Outras críticas foram dirigidas à própria problemática do ativismo. Foram questionados o enfoque na questão da autonomia do juiz, a análise demasiadamente simplificadora dos processos de decisão judicial e a colagem dos agentes 234 a suas identidades institucionais. Afirmam que os termos da problemática são determinados pela questão normativa de estabelecer o papel adequado do Judiciário na democracia e que ela toma o ativismo e seu oposto como dados, e não se questiona sobre a maneira pela qual eles emergiram. Ou seja, não se problematizam as práticas e os processos efetivos pelos quais o tema se constituiu historicamente. Seria necessário indagar as condições e os motivos pelos quais ele apareceu num determinado momento histórico e quais as suas transformações. A partir dessas considerações, os críticos rejeitaram a problemática, mas reconheceram que ela é relevante em sua própria pretensão crítica, uma vez que o problema sobre ativismo e autocontenção indica a maneira pela qual se dá o debate público sobre o Judiciário e a Constituição nos Estados Unidos.

O presente artigo faz uma análise crítica desse debate, com o objetivo de mostrar como nele se coloca o problema da análise do direito como prática normativa nas democracias 
contemporâneas ${ }^{1}$. A conclusão indica alguns caminhos para essa análise, desenvolvidos pelo autor em outro trabalho (Koerner, 2016 [no prelo]). A análise tomou como ponto de partida revisões bibliográficas sobre o tema, citadas na bibliografia, e selecionou para apresentação livros e artigos pioneiros e/ou relevantes para os objetivos propostos.

\section{A emergência do ativismo como problema no debate público norte-americano}

O problema do papel político do Judiciário no governo representativo tem longa história. Na Revolução Francesa, o controle dos magistrados era central, dada a percepção do risco de eles atuarem para restaurar os privilégios por meio da interpretação das leis. No século XIX, nos regimes parlamentaristas e de monarquia constitucional, os juízes ordinários eram excluídos do julgamento de questões de direito público, enquanto no campo privado a decisão judicial era pensada segundo modelos de estrita vinculação à letra da lei ou à estrutura conceitual do direito. Mas ao longo do século a jurisdição administrativa tornou-se semelhante à comum, ao mesmo tempo que se questionavam os modelos estritos de interpretação das leis no direito privado. Estados com organização federal adotaram Constituição escrita, o que implicava uma instância para interpretá-la ao decidir as controvérsias entre os entes da federação. Depois da Primeira Guerra e até o final dos anos 1920, a jurisdição constitucional colocou-se no cerne das tentativas para superar os problemas de instabilidade política dos regimes parlamentaristas, limitar os poderes de governos majoritários apoiados por partidos de massas, particularmente os socialistas, e organizar os novos estados surgidos com a quebra dos impérios europeus, que neces-

1 Para uma discussão bibliográfica sobre o direito como prática social, ver Koerner (2012). 
sitavam estruturas federais e instrumentos para a proteção dos direitos de minorias. O Judiciário norte-americano era tomado como referência, e a justiça constitucional era vista seja como instrumento para racionalizar a democracia parlamentar seja como gouvernement des juges (Baumert, 2009). No Brasil, houve tensões desde o Segundo Reinado até a Primeira República, em particular o confronto entre as prerrogativas do presidente da república e a proteção dos direitos civis e políticos (Koerner, 1998).

Nos Estados Unidos, o problema passa a ser formulado a partir do final da Segunda Guerra sob a forma do ativismo judicial, e se torna central no debate político desde o final dos anos 1960. Arthur Schlesinger teria utilizado pela primeira vez o termo, em artigo na revista Fortune, em 1947, para distinguir os juízes da Suprema Corte em dois campos, do ativismo e da autocontenção. Ele alertava sobre os perigos do ativismo judicial para a democracia e 236 sustentava que o Judiciário só deveria intervir quando se tratasse de defender os direitos políticos. Os termos fundamentais do problema já estavam postos: juízes não eleitos versus leis promulgadas democraticamente; julgamentos fundados em princípios ou voltados a resultados; uso estrito ou criativo dos precedentes; supremacia da democracia versus direitos humanos; direito versus política (Schlesinger apud Kmiec, 2004, pp. 1444-49).

O termo já adquiria carga valorativa por colocar o problema da forma apropriada de decisão judicial em relação às prerrogativas das outras instituições governamentais. $\mathrm{O}$ ativismo era adotado do ponto de vista do observador, era associado ao pragmatismo e ao progressismo político e tinha sentido positivo por valorizar juízes que utilizavam o judicial review para salvaguardar os direitos básicos na democracia. É a partir das decisões da Corte Warren, em especial Brown v. Board of Education, de 1954, que o termo recebeu conotação negativa geral e passou a ser crescentemente 
utilizado, inclusive pelos próprios juízes, para criticar as decisões judiciais ${ }^{2}$.

Assim, se o termo se refere a um problema político duradouro, alcançou novas dimensões políticas a partir daquela época, ao mesmo tempo que se formularam novas teorias sobre ele. O debate tem duas dimensões inseparáveis: primeiro, o seu uso normativo e analítico, e, segundo, a sua utilização como recurso discursivo no processo político. No que segue, serão apresentadas linhas gerais do termo em teorias normativas e em ciência política, acompanhadas das críticas aos termos e à própria problemática. As implicações políticas serão apresentadas na conclusão.

\section{$\mathbf{0}$ ativismo judicial como problema normativo}

O debate normativo é marcado por diferentes concepções sobre o papel apropriado das cortes e das técnicas de decisão judicial. Discutem-se as relações entre representantes eleitos e juízes não eleitos, ou a conciliação entre controle da constitucionalidade e democracia. Este é o tema central, a obsessão, da reflexão acadêmica jurídico-constitucional norte-americana (Lindquist e Cross, 2009, p. 21; Friedman, 2002).

Nos anos 1950, os juristas acadêmicos enfrentavam o problema de justificar a atuação da Suprema Corte, marcada por um duplo standard, o de se autolimitar em questões no campo econômico, mas inovar em decisões para fortalecer os direitos civis e políticos. Os juristas progressistas formados no período anterior ao New Deal colocavam em primeiro plano a crítica à legitimidade democrática da Suprema Corte e valorizavam as políticas promovidas por leis gerais e planos governamentais, voltados à sociedade em seu conjunto. Por sua vez, os

\footnotetext{
2 Kmiec (2004, pp. 1443 e 1459, nota 105) conta uma média de 450 artigos por ano que utilizam o termo, em 2003. O uso era crescente também em decisões judiciais, federais e estaduais.
} 
conservadores haviam adotado, até o New Deal, a doutrina tradicional segundo a qual a Suprema Corte atuava para a proteção dos direitos contra decisões arbitrárias da maioria. Mas o pensamento jurídico formalista, que fundamentava a separação entre direito e política, havia sido desacreditado completamente pelo pensamento jurídico realista, que reconhecia a indeterminação das decisões judiciais e sua vinculação a preferências e a fins ${ }^{3}$. Assim, os conservadores criticavam nos anos 1950 as decisões da Corte do ponto de vista dos seus resultados, apontando-as como errôneas, mas sem atacar diretamente o judicial review (Friedman, 2002). Desse modo, os conservadores tendiam a valorizar a Suprema Corte, mas seu modelo de decisão judicial precisava superar o formalismo enquanto os progressistas precisavam justificar as decisões pelos direitos civis em termos que ultrapassassem o subjetivismo atribuído à decisão judicial pelo realismo.

238 Os conflitos entre os juízes no interior da Suprema Corte sobre a legitimidade e extensão do judicial review traduziam-se em posições intelectuais antagônicas no campo acadêmico, representado pelas escolas de Harvard (teoria do legal process, que defendia a distinção entre raciocínios jurídico e político, sendo aquele baseado em princípios jurídicos neutros) e de Yale (que defendia o realismo jurídico, para o qual as decisões judiciais eram consideradas uma espécie de raciocínio político). Nesse ponto, o debate sobre a dificuldade contramajoritária era no sentido de justificar o judicial review, apesar das imbricações entre o jurídico e o político nas decisões judiciais, em especial as da Suprema Corte (Friedman, 2002).

\footnotetext{
3 Os formalistas pensam a decisão judicial como uma operação lógica de subsunção do caso particular à norma geral. Os realistas afirmam que, dado que não é possível determinar de forma unívoca o significado e efeitos da norma geral nos casos particulares, a decisão judicial comporta um elemento de vontade do juiz na escolha de meios e fins.
} 
A dificuldade contramajoritária, formulada por Alexander Bickel (1986 [1962]), ofereceu algumas chaves para as fundações intelectuais do moderno conservadorismo constitucional. Ele justificava o controle da constitucionalidade, mas afirmava a sua excepcionalidade, porque, quando a Suprema Corte declara inconstitucional um ato normativo dos outros poderes, ela contraria a vontade atual dos representantes do povo e assim exerce o controle não em favor, mas contra a maioria prevalecente. Para ser justificado, o controle deveria ter seus contornos precisamente definidos e ser exercido de forma autocontida, pois as leis deveriam ser invalidadas apenas quando fossem claramente contrárias a princípios neutros. Assim, a ideia de autocontenção judicial justificava o controle da constitucionalidade, mas também o seu uso limitado (Bickel, 1986 [1962], pp. 16-17 e 27; Lindquist e Cross, 2009, p. 22).

Nos anos 1970, os conservadores passaram a utilizar a noção de intenção original dos fundadores e de sentido original da Constituição para definir o papel da Suprema Corte, com o que podiam criticar o governo pelos juízes, sem atacar de frente o próprio Poder Judiciário. O originalismo propugnava que os juízes deveriam determinar o significado da Constituição tal qual ela foi ratificada ou emendada, pois seria este o significado aprovado pelo povo e, portanto, o legítimo. Se orientassem suas decisões pelo significado atual da Constituição, os juízes estariam de fato emendando-a e, pois, criando normas constitucionais ilegítimas porque distintas das regras determinadas pelo próprio artigo $\mathrm{V}$ da Constituição para a sua emenda. O originalismo oferecia uma teoria coerente para os casos em que o Judiciário deveria ser deferente aos outros poderes ou atuar na proteção de direitos, no que se colocavam em primeiro plano as liberdades, a propriedade e o federalismo (Keck, 2004, p. 154).

Robert Bork (1965) e Raoul Berger (1977) lideraram uma geração de pesquisadores originalistas que enfatizaram 
a segurança de uma Constituição escrita para persuadir a Corte a limitar o exercício de seus poderes de proteção aos direitos. Para Bork, dada a incompatibilidade do judicial review com o princípio majoritário, o critério de justificação para a decisão judicial seria a sua adequação à vontade dos "pais fundadores" da Constituição. A Corte deveria exercer seus poderes apenas se justificada por uma teoria derivada da Constituição e não poderia decidir baseada em objetivos de políticas, pois isso ultrapassava seu mandato. Seu entendimento era baseado no relativismo ético e ceticismo quanto aos direitos constitucionais e insistia que, nas situações em que o material constitucional não especificasse claramente o valor constitucional a ser preferido, não haveria maneira de, com base em princípios, preferir um valor humano ou outro e, portanto, a Corte deveria se abster de decidir (Keck, 2004, pp. 152-54).

O livro de Raoul Berger, Government by Judiciary, de 1977, 240 é um marco como panfleto de crítica contra a Suprema Corte. Ele defendia que a intenção original dos autores da Constituição não foi criar uma Corte que agisse como uma convenção constitucional permanente, mas de policiar o respeito aos limites desenhados pela Constituição. A Corte deveria se manter vinculada ao sentido original, no qual a Constituição foi aceita e ratificada pela nação, para manter um governo consistente e estável. No caso da Décima-Quarta Emenda, os objetivos do legislador haviam sido limitados e, pois, a expansão, pela Corte Warren, da igual proteção para outros domínios violava outros princípios da Constituição, como as atribuições dos estados. Ao interpretar a emenda em sentido diametralmente oposto àquela intenção original, a Corte teria passado a reescrever a Constituição e utilizado autoridade que não detinha. Com isso, ela teria ferido as bases do governo constitucional e perdido o respeito do público, o que era a essência da sociedade democrática. Cabia aos acadêmicos fortalecer a consciência pública de 
que a Corte havia transbordado os seus limites e que lhe faltava legitimidade pública. Sugeria, ainda, medidas para controlar os magistrados, como excluí-los de decisões sobre políticas públicas ou expô-los à aprovação popular (Berger, 1977, pp. 1-10, 407-409, 415-18).

É nesse contexto que a doutrina da Law and Economics na Universidade de Chicago recebe impulsos que a tornariam o mainstream no pensamento jurídico norte-americano. Acrescentaram à crítica de falta de legitimidade democrática do Judiciário a dos malefícios da "engenharia social liberal", na qual as cortes estariam engajadas, dada a falta de capacidade institucional para administrar instituições governamentais complexas e alcançar amplas reformas sociais. Nathan Glazer observava, em 1975, que se estava diante de um "Judiciário imperial", que contrariava a vontade popular e afirmava que os ramos políticos do governo teriam mais recursos que as cortes para determinar a melhor maneira de responder a problemas públicos e, se não haviam tratado certos problemas particulares, era porque haviam concluído que não havia conhecimento, recursos ou simplesmente vontade para fazê-lo. Esses argumentos eram colocados por outros conservadores como Donald Horowitz, e constitucionalistas, como Philip Kurland (Keck, 2004, pp. 140-41).

As críticas estridentes continuaram no debate público ${ }^{4}$. O livro de Mark Levin, Men in black: how the Supreme Court is destroying America, de 2005, atribui a juízes ativistas o abuso do seu mandato constitucional, ao produzirem leis para impor suas crenças e preconceitos pessoais ao resto do país (Roosevelt III, 2006, pp. 12-13). Christopher Wolfe (1997) atribui como causa do ativismo os modelos de decisão judicial do pensamento evolucionista e sociológico, para os quais a

4 Outro exemplo é o livro de Carter (1973). Sobre a estratégia de expansão do pensamento conservador no campo jurídico, ver Teles (2008). 
decisão deveria ser informada pelos processos sociais e voltada a governá-los, o que implicava a não diferenciação dos papéis de legislar e de julgar. O caso Brown teria sido o passo crucial na passagem ao ativismo contemporâneo, pois, em vez de se fundar na intenção original da Décima-Quarta Emenda, a Corte se baseou em dados de ciências sociais que levavam à conclusão de que a doutrina "iguais, mas separados" produzia efeitos de desigualdades entre brancos e negros, o que era questionado na época por outras evidências. Estimulados pelo sucesso, os juízes passaram a atuar como reformadores sociais em outros casos. Ele propõe uma teoria normativa oposta à teoria do realismo jurídico, no que rejeita a perspectiva sociológica e distingue a legislação da interpretação e aplicação da lei (Wolfe, 1997, pp. 2 e 19).

Em defesa do ativismo judicial, adotaram-se argumentos elitistas, segundo os quais o Judiciário seria uma instância formada por homens experimentados e prudentes com o papel 242 de limitar os poderes de representantes eleitos, suplementar aos demais poderes governamentais e preservar a Constituição (Miller, 1982). O ativismo judicial não seria mais do que a atuação da Corte em decisões fundadas em princípios e regras constitucionais, de defesa da Constituição contra as invasões e excessos dos outros poderes. A Suprema Corte tinha o papel de exercer a liderança moral perante a população, como uma instância oracular. O cerne da sua missão seria o fortalecimento e atualização do código simbólico que estrutura o conjunto da sociedade, dado pela ideia de dignidade humana. Este serviria de orientação para as suas decisões, que permitiriam aos cidadãos ascenderem para além das pequenas tiranias cotidianas e ver a totalidade social (Miller, 1982, pp. 191-92). Outro argumento é que a maioria das decisões consideradas ativistas eram aceitas e defendidas pela sociedade e, se a Corte adotasse a estrita deferência aos demais poderes, manteria em vigor leis que violam a Constituição (Roosevelt III, 2006, p. 174; Lindquist e Cross, 2009, p. 25). 


\section{A validade e o refinamento analítico do termo}

Desde que começou a ser utilizado, o termo ativismo, assim como o seu complemento, a autocontenção, teve sua validade posta em questão e foram formuladas propostas para torná-lo mais preciso e empiricamente útil. No volume Supreme Court: activism and restraint, organizado por Halpern e Lamb (1982), a primeira coleção de textos de ciência política que tratou o debate sob uma pluralidade de perspectivas, vários colaboradores mantiveram o termo. Outros cogitaram seu abandono como categoria para a análise, dados os seus problemas empíricos e ambiguidades.

Para Marvin Shick (1982), o elemento central do ativismo seria a noção de que os juízes devem decidir os casos, sem evitar questões relevantes ou complexas, e que o Poder Judiciário deveria ser utilizado amplamente, expandindo o escopo e o volume da litigação e interpretação constitucional. $\mathrm{O}$ ativismo seria a confiança no papel judicial para estabelecer novas normas - para legislar; os juízes não seriam apenas orientados segundo políticas, mas o fariam de forma aberta, esforçando-se para conformar o direito para realizar as suas preferências; eles acreditariam que haveria um remédio judicial para os males sociais levados à Corte e que seria dever do juiz promover direitos e valores sociais; e, enfim, adotariam um estilo de decisão, com uso excessivo da polêmica e de recursos retóricos, com os quais colocariam em primeiro plano a exortação do bom e do justo para educar o público e convencer seus colegas. Por sua vez, a autocontenção indicaria aos juízes evitarem questões que geram conflitos ou complexas e que apenas escolhessem os casos que envolvessem claramente questões de direito (Shick, 1982, pp. 44-49).

Bradley Canon (1982) propôs uma estrutura para a análise do ativismo judicial aplicada a decisões da Suprema Corte em direito constitucional, na qual fossem removidos ou minimizados os componentes ideológicos ou motivações 
associadas ao termo. Ele designaria uma significativa mudança na política pública, provocada por uma decisão da Suprema Corte e que teria a sua legitimidade questionada porque seria percebida como inadequada para as crenças articuladas sobre o papel apropriado da Corte no sistema político. Valendo-se dos critérios postos pelo debate constitucional, ele define seis dimensões para caracterizar o fenômeno $^{5}$ e distingue três graus: alto, médio ou inexistente. Sua estrutura caracteriza o ativismo como um fenômeno multidirecional e gradativo, que não tem relação linear com ideologias políticas ou apreciações sobre a correção das decisões judiciais enquanto tais. O quadro analítico permitiria medir as diversas decisões da Suprema Corte, organizadas segundo temas, em ordem temporal ou por juiz (Canon, 1982, pp. 386-89; 413-14).

As tentativas em políticas públicas e política comparada de definir dimensões analíticas de categorias para a 244 pesquisa empírica dos modelos do ativismo e da judicialização da política adotaram os critérios propostos pelos conservadores para a qualificação normativa do comportamento dos juízes e o questionamento da legitimidade da atuação da Suprema Corte nos anos 1970 (Holland, 1991; Jackson e Tate, 1992; Tate, 1992). Assim, Donald Jackson (1992) parte das doutrinas dos neoconservadores William Rehnquist (nomeado Chief Justice por Reagan) e Edwin Meese (Attorney General do governo Reagan) para concluir sobre as dificuldades em estabelecer uma definição rigorosa sobre o que devem fazer os juízes e os representantes eleitos. No entanto, formula um framework for comparative analysis, tomando como base o modelo institucional norte-

\footnotetext{
5 Ele as define como escalas que se referem a: (1) intervenção judicial nos processos democráticos; (2) estabilidade das decisões judiciais; (3) interpretação construtiva ou contextual das normas; (4) decisão judicial sobre políticas substantivas em vez da preservação de processos democráticos; (5) limitação da discricionariedade dos governantes; e (6) substituição dos políticos pelos juízes em decisões relevantes.
} 
-americano e as categorias formuladas por aqueles autores. Nelas se supõe uma clara divisão entre o campo das políticas públicas, próprio à decisão majoritária, e o da proteção de direitos fundamentais, próprio à decisão judicial. Os termos originalismo e deferência dos juízes aos legisladores e administradores são a referência para o quadro de análise elaborado para ser utilizado em pesquisas comparadas.

Holland (1991) considera o ativismo como a adoção de técnicas e objetivos não compatíveis com o papel apropriado das cortes. O caso Lochner seria indicativo de que o ativismo judicial emerge quando os juízes não se sentem mais restringidos pelo direito (law), e sua imaginação é capturada por doutrinas variadas como o positivismo jurídico, o historicismo e a jurisprudência sociológica. O caso Brown v. Board of Education, de 1954, mostraria uma corte voltada a promover a mudança social, realizando uma espécie de engenharia social, com o uso de pesquisas sociológicas e decisões prospectivas, que visariam alterar atitudes e valores públicos e redistribuir poder político e riqueza. O ativismo teria causas sociais mais gerais, como a abertura do sistema político do país aos grupos de pressão, que combinariam a sua atuação junto aos legisladores à ação judicial, a perda do sentido de comunidade e a expansão da moralidade individualista, a emergência do legislador profissional interessado na reeleição e a crise de legitimidade dos Estados capitalistas, com a perda de confiança nos representantes e funcionários. Esses fatores, somados ao comportamento inadequado dos juízes, faria o ativismo e a judicialização aumentarem nos anos subsequentes (Holland, 1991, pp. 17-20, 26-29). Assim, um quadro idealizado de nítida separação dos poderes e cultura cívica soma-se à teoria de que a decisão judicial deveria ser limitada ao direito objetivo posto na norma constitucional. 
No modelo proposto por Tate e Vallinder (1995), o ativismo é uma das condições para a judicialização da política, e é definido como a orientação do juiz para contrariar a política majoritária. O tema da judicialização da política foi proposto para um seminário internacional em 1992, publicado em uma revista (IPSR, 1994) e, em seguida, no livro organizado por Tate e Vallinder. Ele se tornou central no debate de política comparada, ciência política e direito constitucional em outras partes do mundo, incluindo o Brasil.

As tentativas de fazer pesquisa empírica sobre o ativismo continuaram. O livro de Lindquist e Cross (2009), Measuring judicial activism, propõe estabelecer um conceito operacional de ativismo judicial, pois eles consideram que o termo capturaria um importante aspecto dos governos contemporâneos, em que as cortes têm se envolvido em políticas públicas e levam o Legislativo a adotar as políticas determinadas por elas. Apesar da dificuldade de mensura246 ção, poder-se-ia reconhecer "mais ou menos" ativismo, com variações entre países e ao longo do tempo. O ativismo seria um polo de uma escala contínua, cujo oposto seria a contenção judicial (Lindquist e Cross, 2009, pp. 30-31).

Yung (2011) propõe uma maneira sistemática de medir os níveis relativos de ativismo dos juízes com base na propensão de o juiz privilegiar o seu próprio julgamento, colocando-o acima de outro ator constitucionalmente significativo. Ele simplesmente mede a taxa na qual os juízes privilegiaram sua própria visão sobre a de outros. Seu estudo enfoca tribunais de apelação, toma todas as decisões, e não só as que envolvem o judicial review, e procura identificar o padrão geral de comportamento dos juízes. Ao examinar como os juízes respeitam os padrões tanto de deferência ou não no agregado, ele determinou a taxa, relativa a outros juízes, em que um juiz substitui pelo seu julgamento o de um juiz inferior. No entanto, não encontrou correlação do ativismo com a ideologia do juiz. 
As críticas ao uso analítico do termo têm sido tão duradouras quanto as tentativas de defini-lo. Já em 1955, McWhinney criticava os termos ativismo e contenção judicial, apontando que eles não eram excludentes nem contrapostos, pois ambos poderiam ser encontrados até num mesmo voto (Kmiec, 2004, pp. 1451-52). Na coletânea organizada por Halpern e Lamb em 1982, vários autores levantavam objeções: seria difícil delinear as bases e limites da contenção judicial, pois os juízes raramente adotam as máximas de forma consistente (Lamb, 1982). Os juízes seriam inconsistentes ao longo do tempo, exerceriam a contenção de forma seletiva e tenderiam a favorecer certas ideologias ou interesses (Champagne e Nagel, 1982, pp. 315-16). O comportamento dos juízes não seria explicado pela deferência, pois seus votos seriam expressões de suas atitudes em relação às políticas. A autocontenção significaria que os juízes seriam deferentes ao juízo dos outros poderes a respeito de uma questão apenas quando eles aprovam o resultado desse juízo. Se eles são deferentes, o fazem de forma calculada, pois, como qualquer mortal, deferem às ideias e instituições que aprovam (Spaeth e Teger, 1982, p. 278; Novak, 1982).

Roosevelt III (2006) indica que a contenção judicial supõe uma espécie de aplicação direta da Constituição, o que seria uma fantasia, em particular em casos relevantes e controversos. O significado claro não está presente em nenhuma das decisões constitucionais controvertidas, pois elas tratam justamente de situações em que não há consenso nem a respeito de quais serão as bases a partir das quais o debate poderá ser colocado ${ }^{6}$. As críticas de que a Corte se

6 O mesmo vale para o originalismo que, segundo ele, não é capaz de oferecer respostas corretas para inúmeras questões e o juiz poderia eventualmente se valer de evidências históricas parciais para chegar a decisões segundo suas preferências políticas. Além disso, poder-se-ia supor a situação em que o significado de um dispositivo constitucional se mantém o mesmo, mas a sua aplicação mudou, pela alteração dos critérios de seu uso (Roosevelt III, 2006, pp. 50-51). 
afasta do significado claro da Constituição e que o substitui pelas motivações pessoais dos juízes não passam de insultos a eles e não significam mais do que as decisões da Corte serem contrárias às preferências do próprio enunciador (Roosevelt III, 2006, pp. 6; 15-21).

\section{Críticas à problemática do ativismo judicial}

A problemática posta pelo debate sobre o ativismo judicial foi redefinida ou rejeitada por alguns autores, que apontaram para as questões subjacentes àquele debate e propugnaram a pesquisa histórica e a análise política da sua emergência.

Barry Friedman (2002), elaborou uma história intelectual e política da "obsessão contramajoritária” no pensamento jurídico-constitucional norte-americano da segunda metade do século XX. O problema é posto com o objetivo de avaliar a atuação da Suprema Corte. Ele se concentra em decisões individuais, com análises de curta duração e

248 constrói explicações das decisões judiciais baseadas em opiniões e comportamentos individuais. Ele tem uma compreensão inadequada e simplificada da dinâmica da democracia norte-americana. Tem como resultado uma atividade acadêmica que propõe sucessivas soluções ao problema sem examiná-lo criticamente nem elaborar as suas fundações. A pesquisa deveria ser baseada empiricamente, para combinar a reflexão normativa com o entendimento de como as decisões judiciais operam efetivamente. Deveria considerar também outros problemas, como o papel de outras instituições não eleitas (banco central, agências reguladoras), o Judiciário como um todo e os efeitos do judicial review sobre a dinâmica da democracia norte-americana (Friedman, 2002, pp. 156-67). Seu trabalho histórico-crítico coloca em relevo o caráter situado e contingente do debate sobre o ativismo, em que o uso do termo revela pouco mais do que a posição adotada pelo autor sobre arranjos institucionais ou resultados de decisões específicas. 
Kmiec (2004) conclui que, apesar de o termo ter sentidos distintos e contraditórios, ele é relevante por abrir o debate sobre o Judiciário. Ele pode ser um ponto de partida proveitoso para a conversação sobre temas como a melhor maneira de interpretar a Constituição, qual o escopo apropriado do judicial review, quanto a decisão deve se vincular aos precedentes e a deferência apropriada dos juízes aos outros poderes (Kmiec, 2004, p. 1477).

O exercício apropriado da autoridade judicial coloca uma questão de legitimidade. Os destinatários da decisão judicial examinam se ela é uma razoável tomada de posição em termos de deferência aos entes governamentais cujas decisões foram sujeitas à revisão. Para Roosevelt III, a Corte exerceria um nível inadequado de deferência ao recusar ou aderir cegamente à decisão de outro poder governamental, e assim a decisão seria criticável ao ser recebida como inaceitável pelos destinatários. O juízo não implicaria que ela foi motivada pelas preferências dos juízes ou que foi errônea, pois o significado da Constituição não pode ser determinado de forma inteiramente objetiva ${ }^{7}$. Então, o grau apropriado de deferência não seria apenas uma relação posta pelo texto constitucional ou pela vontade contraposta dos atores institucionais, pois a legitimidade da decisão seria a sua razoabilidade, do ponto de vista do entendimento comum sobre o que a Constituição e as leis significam (Roosevelt III, 2006, pp. 3, 36-34, 41-45).

Craig Green (2009) também valoriza os debates cotidianos que ocorrem na comunidade jurídica e política sobre o Judiciário. A relevância do termo ativismo judicial se daria por ele indicar uma maneira de o público avaliar as decisões

\footnotetext{
7 Isso não decorre de deficiências do seu texto, mas porque a sua significação remete à compreensão compartilhada que um povo razoável tem dela, e, além disso, o significado de proposições normativas genéricas não determina como os juízes devem resolver as questões postas concretamente.
} 
dos juízes e seu sentido seria o "abuso do poder não supervisionado, que é exercido fora dos limites do papel do Judiciário". Assim, ele coloca em relevo a responsabilidade de o juiz usar sua discrição de modo a realizar seus julgamentos apropriadamente. As críticas e debates públicos fazem parte das expectativas culturais sobre os juízes e elaboram o controle operativo contra a usurpação judicial. Assim, o termo representaria discussões cruciais sobre o papel judicial, e se referem a padrões culturais, em parte implícitos, da tradição jurídica e que não são estabelecidos em lei (Green, 2009, p. 1197). Os padrões para atribuir o termo ativismo judicial a uma decisão são produzidos por uma mistura de exemplos históricos e princípios prescritivos, o que permite identificar limites à decisão judicial e deixar aberto o caminho para a mudança institucional ${ }^{8}$.

O tema do ativismo judicial indicaria uma função crítica, seria o sinal de uma atividade coletiva e constante de 250 debate na República norte-americana sobre o papel e as formas de atuação apropriadas para o Poder Judiciário. A correção e aceitabilidade das decisões judiciais significam que elas são recebidas e refletidas como a expressão da regra comum de juízo considerada objetivamente válida, porque tendencialmente aceita por todos, para além da sua enunciação.

No entanto, o exercício da função crítica não deve ser referido a uma comunidade política genérica, mas colocado no quadro da organização social e do Estado, e se deve considerar o contexto em que o seu tema central passou a ser o ativismo, isto é, depois das decisões da Corte

\footnotetext{
8 Esses padrões são identificados a partir das normas e formas de atuação existentes num certo momento, com um campo variado e altamente seletivo de exemplos para construir normas judiciais, e aplica apenas princípios com raízes históricas e institucionais em vez de moralidade ou lógica universais. Ele acrescenta que os critérios que adota são familiares, uma vez que são os ordinários do sistema jurídico do país.
} 
Warren em prol dos direitos civis. Além disso, a função crítica pode ser generalizada para a reflexão sobre o direito nas democracias constitucionais, na medida em que indica a problematização das relações entre normatividade jurídica com a racionalidade governamental, as formas institucionais do governo representativo e os saberes sobre indivíduos e populações. O tema do ativismo judicial seria então a maneira pela qual é formulado o problema da objetivação, programação e autorreflexão do direito no debate público e intelectual contemporâneo. A problematização permanente do direito remete a como conhecer e julgar o sistema jurídico, e como identificar suas características e promover sua transformação.

Então, o cerne do debate sobre o ativismo leva à rejeição da problemática posta por ele, bem como a dificuldade contramajoritária e a judicialização. Os autores propõem nova problemática, que deve ser realizada por uma análise política e histórica, assim como a discussão normativa sobre o direito, a prática judicial e o pensamento jurídico nas democracias constitucionais contemporâneas. Essa análise implica outras questões, conceitos e estratégias de pesquisa.

O tema do ativismo judicial coloca o problema de determinar o papel apropriado do Poder Judiciário, o modelo de decisão judicial e o comportamento dos juízes, de modo a justificar a atuação de juízes não eleitos na democracia constitucional. Com ele, supõe-se que haja um padrão histórico objetivo para apreciar e determinar as formas legítimas de atuação dos tribunais e se investe num conjunto de representações sobre o Judiciário - a exterioridade das normas, a abstração das categorias, a neutralidade dos juízes e a fixidez das decisões judiciais. 
Mas as controvérsias sobre a prática judicial são intermináveis e cambiantes, nos termos postos e nas posições assumidas pelos protagonistas. A pluralidade de significados do ativismo na linguagem acadêmica tem variações correlatas em outros campos - nas divergências sobre conceitos e doutrinas jurídicas, nas orientações jurisprudenciais e nas polêmicas políticas sobre os modelos e técnicas de decisão judicial. Desse modo, as propostas de medição do "fenômeno" do ativismo serão sempre relativas aos padrões e instrumentos de medida adotados, mas com elas se perde de vista a emergência do tema e suas relações com as mudanças históricas da prática judicial e da sociedade norte-americana, além de não considerarem adequadamente as interações entre os tribunais e o sistema político.

Para além de apontar as limitações analíticas e o viés normativo do ativismo judicial, observa-se que ele coloca a questão do direito como prática normativa no quadro das 252 democracias constitucionais contemporâneas. Em que grau é possível que padrões de medida normativos para as relações sociais sejam formulados, reconhecidos, aceitos e reivindicados pelos sujeitos? É possível alcançar esses padrões por meio de conceitos e técnicas de decisão judicial?

À análise política do pensamento jurídico coloca-se o desafio de propor questões estratégicas de pesquisa, que reconheçam o caráter crítico desses debates, de modo a ser capaz de trabalhar, para além das pretensões de logicidade e de unidade de teorias e conceitos sobre o direito, os conflitos, fissuras e incertezas do direito, enquanto experiência social de prática e reflexão. De uma perspectiva mais ampla, trata-se de indagar por que o tema surgiu naquele momento determinado, quais as forças e programas que se enfrentam e qual é a história efetiva de sua emergência ${ }^{9}$.

\footnotetext{
9 Esses temas foram indicados em Koerner (2013) e desenvolvidos em Koerner (2016 [no prelo]).
} 


\section{Andrei Koerner}

é professor de Ciência Política do Instituto de Filosofia e Ciências Humanas da Universidade Estadual de Campinas (IFCH-Unicamp); pesquisador do Instituto Nacional de Pesquisas sobre os Estados Unidos (INCT-Ineu) e pesquisador associado do Cedec.

\section{Bibliografia}

BAUMERT, R. 2009. La découverte du juge constitutionnel, entre science et politique. Paris: LGDJ.

BERGER, R. 1977. Government by Judiciary. Cambridge, Ma: Harvard University Press.

BICKEL, A. 1986 [1962]. The least dangerous branch: the Supreme Court at the bar of politics. New Haven: Yale University Press.

BORK, R. H. 1965. The tempting of America: the political seduction of the law. New York: Free Press.

CANON, B. 1982. A framework for the judicial activism. In: HALPERN, S.; LAMB, C. (orgs.). Supreme Court: activism and restraint. Lexington: Lexington Books.

CARTER, J. D. 1973. The Warren Court and the Constitution: a critical view of judicial activism. Gretna: Pelican Publishing.

CHAMPAGNE, A.; NAGEL, S. 1982. The advocates of restraint: Holmes, Brandeis, Stone, and Frankfurter. In: HALPERN, S.; LAMB, C. (orgs.). Supreme Court: activism and restraint. Lexington: Lexington Books.

FRIEDMAN, B. 2002. The birth of an academic obsession: the history of the contermajoritarian difficulty. Yale Law Journal, v. 112, n. 2, pp.153-259.

GREEN, C. 2009. An intellectual history of judicial activism. Emory Law Journal, v. 58, n. 5, pp. 1195-263.

HALPERN, S.; LAMB, C. (orgs.). 1982. Supreme Court: activism and restraint. Lexington: Lexington Books.

HOLLAND, K. 1991. Judicial activism in comparative perspective. New York: St. Martin Press. IPSR - International Political Science Review, v. 15, n. 2, 1994.

JACKSON, D. 1992. Original intent, strict construction and judicial review: a framework for comparative analysis. In: JACKSON, D.; TATE, C. N. (orgs.). Comparative judicial review and public policy. Westport: Greenwood Press.

JACKSON, D.; TATE, C. N. (orgs.). 1992. Comparative judicial review and public policy. Westport: Greenwood Press. 
KECK, T. 2004. The most activist Supreme Court in history: the road to modern judicial conservatism. Chicago: The University of Chicago Press.

KMIEC, K. 2004. Origin and Current Meanings of "Judicial Activism". California Law Review, v. 92, n. 5, pp.1441-77.

KOERNER, A. 1998. Judiciário e cidadania na Constituição da República brasileira. São Paulo: Depto. de Ciência Política da FFLCH-USP/ Hucitec [Curitiba: Juruá, 2010, 2. ed.]. 2012. A história do direito como recurso e objetivo de pesquisa. Diálogos (Maringá. Online), v. 16, n. 2, pp. 627-62.<DOI 10.4025/ dialogos.v16i2.665>. 2013. Ativismo judicial? Jurisprudência constitucional e política no STF pós-88. Novos Estudos Cebrap, n. 96, pp. 69-86. 2016 [no prelo]. A Corte Warren no debate sobre o ativismo judicial nos Estados Unidos. In: Política e direito na Suprema Corte norte-americana: debates teóricos e estudos de caso. Ponta Grossa/São Paulo: EdUEPG/EdUnesp.

LAMB, C. 1982. Judicial restraint on the Supreme Court. In: HALPERN, S.; LAMB, C. (orgs.). Supreme Court: activism and restraint. Lexington: Lexington Books.

254 Washington, DC: Regnery.

LINDQUIST, S.; CROSS, F. 2009. Measuring judicial activism. Oxford: Oxford University Press.

MILLER, A. 1982. In defense of judicial activism. In: HALPERN, S.; LAMB, C. (orgs.). Supreme Court: activism and restraint. Lexington: Lexington Books.

NOVAK, D. 1982. Economic activism and restraint. In: HALPERN, S.; LAMB, C. (orgs.). Supreme Court: activism and restraint. Lexington: Lexington Books.

ROOSEVELT III, K. 2006. The myth of judicial activism: making sense of Supreme Court decisions. Yale: Yale University Press.

SHICK, M. 1982. Judicial activism in the Supreme Court. In: HALPERN, S.; LAMB, C. (orgs.). Supreme Court: activism and restraint. Lexington: Lexington Books.

SPAETH, H.; TEGER, S. 1982. Activism and restraint: a cloak for the justices' policy preferences. In: HALPERN, S.; LAMB, C. (orgs.). Supreme Court: activism and restraint. Lexington: Lexington Books.

TATE, C. N. 1992. Comparative judicial review and public policy: concepts and overview. In: JACKSON, D.; TATE, C. N. (orgs.). Comparative judicial review and public policy. Westport: Greenwood Press. 
TATE, C. N.; VALLINDER, T. 1995. The global expansion of judicial power. New York: New York University Press.

TELES, S. M. 2008. The rise of conservative legal movement: the battle for control of the law. Princeton: Princeton University Press.

WOLFE, C. 1997. Judicial activism: bulwark of freedom or precarious security? Plymouth: Rowman \& Littlefield.

YUNG, C. R. 2011. Flexing judicial muscle: an empirical study of judicial activism in the Federal Courts. Northwestern University Law Review, v. 105, n. 1, pp. 1-60. 


\section{ATIVISMO JUDICIAL COMO PROBLEMA INTELECTUAL E POLÍTICO NOS ESTADOS UNIDOS: UMA ANÁLISE CRÍTICA}

\section{ANDREI KOERNER}

Resumo: $\mathrm{O}$ artigo apresenta uma análise crítica do debate acadêmico e político sobre o ativismo judicial nos Estados Unidos. Ele apresenta, em primeiro lugar, a emergência do ativismo como um problema de debate público do país, e, em segundo lugar, as questões normativas e analíticas que ele suscita. Na seção final, apresenta os argumentos dos que rejeitam a própria problemática do ativismo judicial. $\mathrm{O}$ artigo sugere, em conclusão, a adoção de outra perspectiva e questões para a pesquisa sobre o direito como prática normativa nas democracias constitucionais contemporâneas.

Palavras-chave: Ativismo Judicial; Pensamento Jurídico Norte-Americano; Suprema Corte; Judiciário e Cidadania; Análise Política do Pensamento Jurídico.

\section{THE JUDICIAL ACTIVISM AS AN INTELLECTUAL AND POLITICAL PROBLEM IN THE UNITED STATES: A CRITICAL ANALYSIS}

Abstract: The article presents a critical analysis on the academic and political debate about judicial activism in the United States. It presents, firstly, the emergence of activism as a problem in the public debate, and, secondly, the normative and analytical questions that it raises. In the final section, it shows the arguments of those who reject such problematic of the judicial activism. The article suggests, in conclusion, adopting another perspective and issues for research on law as a normative practice in contemporary constitutional democracies.

Keywords: Judicial Activism; American Legal Thinking; Supreme Court; Judiciary and Citizenship; Political Analysis of the Legal Thought.

Recebido: 23/10/2015

Aprovado: 07/10/2016 